\title{
DIŞBÜKEY VE İÇBÜKEY YÜZEYLERİN KÜRESEL PARMAK FREZELENMESİNDE TAKIM SEHİMİNE BAĞLI FORM HATALARININ BELİRLENMESİ
}

\author{
Arif Gök ${ }^{1 *}$, Cevdet Göloğlu ${ }^{2}$, H. İbrahim Demirci ${ }^{3}$ \\ 1* Amasya Üniversitesi, Teknoloji Fakültesi, Makine Mühendisliği, 05000 Amasya \\ ${ }^{2}$ Karabük Üniversitesi, Mühendislik Fakültesi, Makine Mühendisliği, 78050 Karabük \\ ${ }^{3}$ Karabük Üniversitesi, Teknoloji Fakültesi, Endüstriyel Tasarım Mühendisliği, 78050 Karabük \\ arif.gok@amasya.edu.tr, cgologlu@karabuk.edu.tr, hdemirci@karabuk.edu.tr
}

(Geliş/Received: 27.07.2012; Kabul/Accepted: 13.03.2014)

\begin{abstract}
ÖZET
Eğimli yüzeylerin küresel parmak frezelenmesinde, değişken yüzey formu kesici takım üzerinde değişken kesme kuvvetlerine neden olmaktadır. Kesme kuvvetleriyle oluşan esnemeler parça üzerinde göz ardı edilemeyecek form hataları oluşturabilmektedir. Sehim değerlerinin ve buna bağlı form hatalarının bulunması, üretim için uygun toleranslar içinde kalınması ve maliyetlerin azaltılması açısından önem taşımaktadır. Çalışmada EN X40CrMoV5-1/DIN 1.2344 sıcak takım iş çeliğinin TiAlN kaplamalı küresel kesici ile dışbükey ve içbükey yüzeylerin frezelenmesinde takım sehimine bağlı form hatalarını değerlendirilmesi hedeflenmiştir. Farklı takım yolu stratejileri ve kesme parametrelerinin ilgili parametre seviye aralıklarında deneyler gerçekleştirilmiştir. Deneylerde endüktif sensörler ile işleme süresince dinamik takım sehimi kaydedilmiştir. 3B optik tarama ile işlenen deney numunelerin takım sehimine bağlı form hataları tespit edilmiştir. Ölçülen takım sehim değerleri ve 3B optik tarama form hata ölçüm değerleri karşılaştırılmıştır. Dışbükey ve içbükey yüzey formları için tırmanma bölgelerinde, frezeleme pozisyon açısının $45^{\circ}$ ile $60^{\circ}$ aralığında en fazla takım sehimi ve form hatası tespit edilmiştir. Aynı zamanda, en büyük sehimin oluştuğu bölgeler, optik taramalardan elde edilen en büyük form hata bölgelerinin olduğu gözlemlenmiştir. Çalışma sonucunda, kesici takım sehiminin neden olduğu form hatalarının tespitinde, dinamik ölçümlerinden elde edilen değerlerin optik tarama sonucunda elde edilen form hataları ile örtüştüğü görülmüştür.
\end{abstract}

Anahtar kelimeler: Eğimli yüzeyler, küresel parmak frezeleme, takım sehimi, form hatası, optik tarama

\section{DETERMINATION OF FORM DEFECTS DEPENDING ON TOOL DEFLECTION IN BALL END MILLING OF CONVEX AND CONCAVE SURFACES}

\begin{abstract}
Altering in surface forms cause to varying cutting forces in machining of inclined surfaces by ball end mills. The deflections appeared by cutting forces can result in form defects in workpiece. Finding deflection values and related form defects has a significant importance for keeping the production within the appropriate tolerances and in lessening production costs. The aim of this study is to evaluate form defects depending on tool deflection in milling of inclined convex and concave surfaces of EN X40CrMoV5-1/DIN 1.2344 using TiAlN-coated cutting tool. The experiments have been conducted with different cutting tools strategies and cutting parameters at related parameter levels. During machining real time cutting tool deflections are recorded by inductive sensors for the experiments. Then, the form defects of machined specimens caused by cutting tool deflections are determined by 3D optical scanning. The cutting tool deflection values and the values of 3D optical scanning form defects have been compared. The largest cutting tool deflections and form defects are detected at the ramping regions with the milling position angles of $45^{\circ}$ to $60^{\circ}$ for the convex and concave surface types. In addition, the regions that the largest tool deflections have been observed are the same regions with the largest form defects obtained by the optical scanning. As a result, at the determination of form defects caused by cutting tool deflection, the deflection values obtained by real time measurement are coincided with the measurement obtained from 3D optical scanning.
\end{abstract}

Keywords: Inclined surfaces, ball end milling, tool deflection, form defect, optical scanning 


\section{GIRISŞ (INTRODUCTION)}

Otomotiv endüstrisi parça imalatı, türbin bıçakları imalatı ve kalıp imalatı gibi alanlar ön sertleştirilmiş çeliklerin ve parmak frezeleme ile üretimlerini içermektedir. Üretimlerde talep edilen toleranslar çok dardır ve bu yüzden boyutsal hataların en aza indirilmesi zorunludur $[1,2]$. Parmak frezelerden kaynaklanan hatalardan takım üzerindeki salgı ve aşınma öne çıkmaktadır. Bunların yanında, kesme esnasında takım esnemesinden doğan eğilme, üretimde çoğu kez göz ardı edilen önemli bir hatadır [3]. Takımın eğilmesinden kaynaklanan sehim hatalarını hesaplayabilmek için olası etkenlerden, kesme stratejisi, malzeme etkisi, takım boyutları ve yüzeyin eğimi bilinmeli veya takım tezgâhlarının kullanımı esnasinda otonom sistemlerin kurulumu gerekmektedir. Son yıllarda sayısallaştırma sistemlerinin aktif kullanımı bu hatların ortaya çıkarılmasında büyük katkılar sağlamaktadır. Üç boyutlu sayısallaştırma işlemi, var olan bir fiziksel nesnenin üç boyutlu bilgisayar modelini elde etme yöntemidir. Nesneden elde edilen ve ham olan bu bilgi, optik tarama yazılımları ve uygulamaları sayesinde ürün geliştirme sürecinin ilerideki aşamaları için kullanılabilir hale getirilmektedir [4]. Tasarımların değiştirilmesi, yeniden gerçekleştirilmesi ve kalite kontrolü amacıyla, iş parçasının orijinal BDT modeli ile ölçülen iş parçasının oluşturulan BDT verisi karşılaştırılmaktadır [5]. Orijinal BDT verisi ile bu veriye bağlı olarak imal edilmiş parçanın 3B sayısallaş̧ırma verisinin karşılaş̧ırıldığı uygulamalara nadiren rastlanmaktadır. İlgili alan hakkında yapılan çalışmalar genel olarak kesici takımın maruz kaldığ 1 kuvvetlerin oluşturduğu sehim, sehimden kaynaklanan işleme hataları ve optik ölçme yöntemlerinin kullanılması hakkında odaklanmaktadır. Kesme kuvvetlerine bağlı takım sehimi ve yüzey hataları için Ikua vd. [6] işleme hatalarının teorik analizleri üzerine çalışmışlardır. Kesme kuvvetleri eğik (oblique) kesme teorisi tabanlı değerlendirilmiştir. Takım sehiminin sebep olduğu kuvvetlerden kaynaklanan işleme hataları işlenen yüzeyin çeşitli bölgelerinde hesaplanmıştır. Kim vd. [7] kesici takımın eğilmesinden kaynaklanan sehimler yüzünden frezeleme esnasında oluşan üç boyutlu şekil hatalarının analizi için geliştirdikleri yöntemi sunmuşlardır. Lacalle vd. [8] çalışmada sertleştirilmiş çelik yüzeylerin yüksek hızda frezelenmesinde takım sehiminden kaynaklanan boyutsal hataları incelemişler ve ilgili yüzeyler için boyutsal hataları tespit etmişlerdir. Zhang vd. [9] serbest şekilli yüzeylerin frezelenmesinde şekilsel doğruluğa ve yüzey kalitesine çeşitli takım yolu stratejilerinin etkilerini deneysel olarak araştırmışlardır. Optik ölçme yöntemlerinin kullanılmasında ise Elmas vd. [10] işlenmiş bir yüzeyin optik profil ölçme teknikleri (1şık kesiti ve fotometrik görünüm) ile analizi üzerine çalışmışlardır. Vorburger vd. [11] yüzey yapılarının ölçülmesi için optik ve iğneli ölçüm yöntemlerini karşılaştırmışlardır. Optik metotlar ile iğneli ölçümler arasında \%75'e yakın farklar ortaya koymuşlardır. Lin ve Chin [12] eksenel fan bıçaklarının optik taranması için otomatik 3B ölçüm sistemleri üzerine çalışmışlardır. Çalışmada geometrik hesap algoritması ile uygun ölçüm yönünü belirlemişlerdir. Huang vd. [13], Quan vd. [14] and Chen ve Huang [15] fringe izdüşümü optik ölçme yöntemi ile şekillerin ölçümü üzerine çalışmışlardır. Bu sayede fringe izdüşümünün ölçümlerde faydalı bir şekilde kullanılabileceğini göstermişlerdir. Kurt vd. [16] serbest formlu yüzeylerin frezelenmesinde yüzey pürüzlülüğü ve şekil hatalarının azaltılması üzerine çalışmışlardır. Şekil hatalarını değerlendirmede fringe izdüşüm yöntemini kullanarak optik tarama yapmışlardır. Yapılan çalışmalar bireysel olarak yüzey analizlerine göre işleme hatalarının tespiti, koordinat ölçme makinaları ile form hatalarının belirlenmesi, farklı tekniklerin kullanıldığı optik tarama üzerinde yoğunlaşmıştır. Bu çalışmada amaç, eğimli yüzeylerin küresel parmak frezelenme esnasinda kesici takım sehiminin ölçülmesi ve sehimin sebebiyet verdiği form hatalarının tespitidir. $\mathrm{Bu}$ doğrultuda, eğimli yüzeylerin farklı takım yolu hareketleri ve kesme parametreleri altında işlenmesinde oluşan sehim endüktif sensörlerle ölçümü ve yine form hatalarının tespiti için fringe optik tarama yöntemi parçanın taranması gerçekleştirilmiştir.

\section{1 İşleme Stratejileri (Cutter Path Strategies)}

Çalışma kapsamında yapılan deneylerde, dışbükey ve içbükey yüzeylerin frezelenmesi, tırmanma ve kontur takım yolları, aynı yönlü ve zit yönlü frezeleme stratejileri üzerine kurularak gerçekleştirilmektedir. Tırmanma takım yolunda kesici dışbükey veya içbükey yüzeyi paralel çizgiler şeklinde tarayarak işlemektedir. Kontur takım yolunda ise kesici dışbükey veya içbükey yüzeyi dik çizgiler şeklinde tarayarak işlemektedir. Belirlenen bu şartlar altında dört adet işleme tarzı oluşturulmuş ve bunlar; zit yönlü kontur (ZYK), aynı yönlü kontur (AYK), zıt yönlü tırmanma (ZYT) ve aynı yönlü tırmanmadır (AYT) (Şekil 1). Şekil 1'de, $W$ iş mili devri, $R$ dışbükey yüzeyin yarıçapı, $\theta$ frezeleme pozisyon açısı, $a$ kesme derinliği ve $f p$ yanal adımdır. Frezeleme pozisyon açısı, iş parçası daire merkezine göre takımın konumudur. Deneylerde kullanılan iş parçası üzerine $40 \times 30 \times 50 \mathrm{~mm}$ boyutlarında ve $20 \mathrm{~mm}$ yarıçaplarında dış ve içbükey yüzeyler yarım daire adacıklar şeklinde hazırlanmıştır. $\mathrm{Bu}$ yüzeylerin tercihinde, eğimli yüzeylerin dış ve içbükey serbest formlu yüzeylerden meydana gelmesi öncelik oluşturmuş̧ur. 


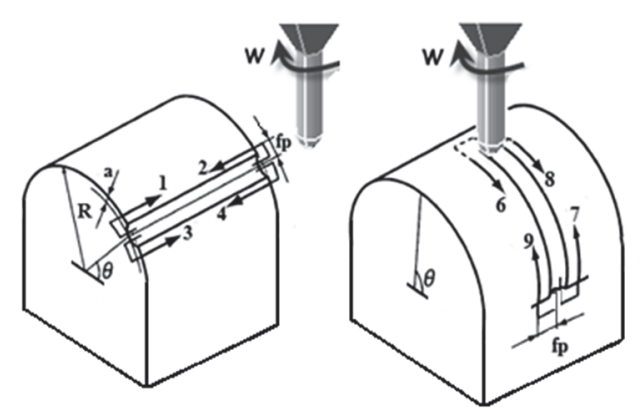

Şekil 1. Takım yolu tarzları: Kontur frezeleme: zıt yönlü (yanal ilerleme çıkış) 1, aynı yönlü (yanal ilerleme çıkış) 2, zıt yönlü (yanal ilerleme iniş) 3, aynı yönlü (yanal ilerleme iniş) 4; Tırmanma frezeleme: zıt yönlü (yanal ilerleme sol) 5, aynı yönlü (yanal ilerleme sol) 6 , zıt yönlü (yanal ilerleme sağ) 7 , aynı yönlü (yanal ilerleme sağ) 8 (Cutter path styles- contouring: up milling (up step over) 1, down milling (up step over) 2, up milling (down step over) 3, down milling (down step over) 4; ramping: up milling (left step over) 5, down milling (left step over) 6 , up milling (right step over) 7, down milling (right step over) 8)

Efektif çap; özellikle küresel solid ya da küresel takma uçlu frezelerin talaş kaldırma esnasında; talaş derinliğine bağlı olarak lineer olmayan bir şekilde artan ya da azalan gerçek takım çapıdır. Efektif çapın takım temas uzunluğunu doğrudan etkilemesinden dolayı talaş kesitini büyüttüğü, dolayısı ile kuvvetleri ve takım sehimini etkilediği bilinmektedir. Küresel takımlarla frezeleme esnasında talaş derinliği takım radyüsünden küçükse efektif çap aşağıdaki formülle hesaplanır.

$D w=2 \times \sqrt{a\left(D_{c}-a\right)}$

Burada, $D w$ efektif çap, $a$ talaş derinliği ve $D_{c}$ takım çapıdır.

\subsection{Parametrelerinin Belirlenmesi (Determination of Parameters)}

Çalışmada, kesici ve kullanılan malzemeye göre son talaş kaldırma operasyonu için işleme tarzına ek olarak üç farklı değişken kontrol edilebilir parametre kullanılmıştır. Bunlar; kesme hızı $(V c)$, ilerleme $(V f)$ ve kesici yanal adımıdır ( $f p)$. Talaş kaldırma operasyonlarında yanal adım değeri, kesici çapının \%5'i alınarak oluşturulmuştur. Kesme hızı ve ilerleme değer aralıkları, kesici üreticisi firmanın (Sandvik Coramant) malzeme ve kesici takıma bağlı olarak önerdiği değerlerdir. $\mathrm{Bu}$ yüzden bu değerlerin en küçük ve en büyük aralıkları firma kataloglarından alınmıştır (Tablo 1). İlgili kontrol parametrelerinin hangi değer aralıklarında etkin olduğunu az deney sayısı ile belirleyebilmek için Taguchi deney tasarımı kullanılmıştır [17, 18]. Kullanılan dört farklı parametre ve her bir parametre için dört farklı seviye için L16 standart dikey dizine göre deney tasarımı yapılmıştır.

\section{3 Üç Boyutlu Optik Tarama İle Sayısallaştırma (Digitizing with Three Dimensional Optical Scanning)}

Kalite kontrol alanında kullanılan yöntemlerden bir tanesi optik tarama yöntemidir. Bu yöntem ile orijinal BDT verisi ve bu veriye bağlı olarak imal edilmiş parçanın 3B sayısallaştırma verisinin karşılaştırılması hedeflenmektedir. Karşılaştırılmalarda kullanılan ASCII STL formatı 3B sistemler tarafindan oluşturulan BDT yazılımları için yerel bir dosya formatıdır. STL dosyaları renk, doku veya diğer yaygın BDT model özniteliklerinin herhangi temsili olmadan üç boyutlu nesnenin sadece yüzey geometrisinin açılayabilmektedir. Deneylerde Breukmann firmasının opto-TOP-HE tarama sistemi kullanılmıştır (Şekil 2) [19]. Numunelerin optik taranmasında fringe izdüşümü yöntemi tercih edilmiştir. Bu yöntemde çoklu 1şık kesitleri başka bir deyişle siyah ve beyaz şeritler halindeki desenler cismin yüzeyine düşürülerek ve bir ya da daha fazla yüksek çözünürlükteki kamera yardımı ile bilgisayar ortamına aktarılarak 3 boyutlu yüzey bilgisi elde edilir [20]. Çalışmada, fringe izdüşümü yöntemi ile elde edilen nokta bulutu öncelikle yüzey modele çevrilmiş ve bu yüzey küçük üçgen yüzeylere (Şekil 3(b)) bölünmüştür [21]. Bu üçgen yüzeyler ise köşelerinin kartezyen koordinatları ve yüzey normal vektörü ile temsil edilmiştir. Temsil edilen bu yüzeylerin Şekil 3(a)'da verilen algoritmada görüldüğü gibi köşeleri üç temel eksende de ifade edilmiş olur. Taramalar ile gerçek parçaların karşılaştırılmasında öncelikle yüzeyin normaline göre belirlemeler yapıldıktan sonra z ekseninde köşe koordinatına göre yerleşim yapılmıştır. Şekil 3'de ASCII STL formatı ile yüzeycik ve normali gösterilmiştir.

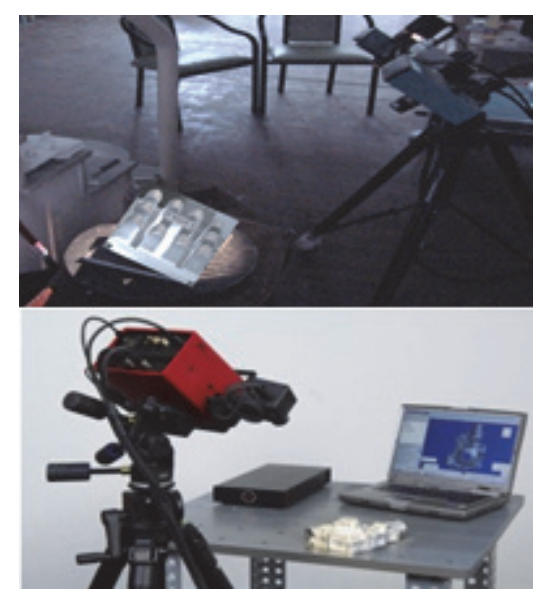

Şekil 2. Üç Boyutlu Optik Tarama İle Form Hatalarının Ölçülmesi (Measurement of Form Defects with Three Dimensional Optical Scanning) 
Tablo 1. Faktör düzeylerinin atanması (Assignment of the levels to factors)

\begin{tabular}{lllll}
\hline Faktörler & Seviye 1 & Seviye 2 & Seviye 3 & Seviye 4 \\
\hline Kesme hızı, $V c(\mathrm{~m} / \mathrm{min})$ & 110 & 120 & 130 & 140 \\
\hline İlerleme, $V f(\mathrm{~mm} / \mathrm{min})$ & 350 & 382 & 414 & 445 \\
\hline Yanal adım, $f p(\mathrm{~mm})$ & 0,8 & 1 & 1,5 & 2 \\
\hline \multirow{3}{*}{ Takım yolu tarzları } & Zit Yönlü & Aynı Yönlü & Zit Yönlü & Aynı Yönlü \\
& Kontur & Kontur & Tırmanma & $\begin{array}{l}\text { Tirmanma } \\
(\text { AYT })\end{array}$ \\
\hline
\end{tabular}

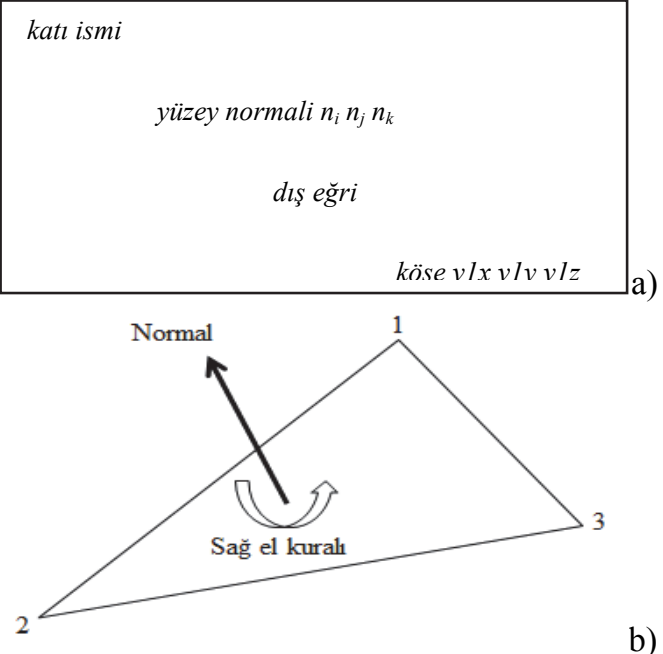

Şekil 3. a) ASCII STL formatı, b) yüzeycik ve normali (ASCII STL format a), surface and its normal b))

BDT yazılımı [22] ile elde edilen model, işlenen parçanın optik taranması ile elde edilen STL (StereoLithography) verisi ile aynı koordinat sistemi üzerine yerleştirilerek, modeller arasındaki farklar analiz edilmiştir. STL verisinin dışbükey veya içbükey bölgesi ile BDT verisinin dişbükey ve içbükey bölgeleri aynı doğrultuda birleştirilmiş ve parçanın düzgün bir duvarı referans alınarak hatalar ortaya çıkarılmıştır. Burada amaç katı model olarak elde edilen işlenmiş parçaya ait BDT verisi ile ulaşılmak istenen hedef yüzey arasındaki farkların analizidir.

\section{DENEYSEL ÇALIŞMA (EXPERIMENTAL STUDY)}

Çalışmada DIN 1.2344 X40CrMoV5-1 (Böhler W302) sıcak iş takım çeliği kullanılmıştır. Malzeme $1650 \mathrm{~N} / \mathrm{mm}^{2}$ akma dayanımı ile 22-25 HRC sertliğe sahiptir. $1020-1080^{\circ} \mathrm{C}$ sicaklikta $25-30$ dakika isıl işleme tabi tutulup yağ içerisinde soğutulduğunda sertliği yaklaşık 50-54 HRC' ye çıkmaktadır. Endüstrideki kullanımına paralel olması açısından sertleştirme yapılmamış, fakat malzeme talaş kaldırma operasyonları tamamlandıktan sonra 1sıl işleme tabi tutulmaktadır. İlgili malzemenin kimyasal özellikleri \% 0,39 C, \% 1,00 Si, \% 0,40 Mn, \% 5,10 Cr, \% 1,30 Mo, \% 0,025 P, \% 1,00 V ve \% 0,005 S'dir. Kesici olarak, değiştirilebilir uçlu (R216-16A20-045), Ø16 $\mathrm{mm}$ silindirik saplı, $30^{\circ}$ helis açılı parmak freze kullanılmıştır. Kesici uç olarak 3 mikron kalınlığında
TiAlN kaplı (R216-16 03 M-M H13A) uçları kullanılmıştır. Dışbükey ve içbükey yüzeylerin işlenmesinde yarı bitirme operasyonu uygulandığ 1 için soğutma sıvısı kullanılmamış ve ölçümler JohnFord VMC 550 dik işleme merkezinde gerçekleştirilmiştir. Deneylerde $\mathrm{x}$, y eksenlerinde kesme kuvvetleri, $\mathrm{x}$ ve $\mathrm{y}$ eksenlerinde sehim değerleri kaydedilmiştir.

$\delta_{x}=\frac{F x(\psi)}{k}, \delta_{y}=\frac{F y(\psi)}{k}$

Burada $\delta_{x}, \delta_{y} x$ ve $y$ yönlerinde meydana gelen takım sehimi, $F x(\psi), F y(\psi) x$ ve $y$ yönlerinde meydana gelen kesme kuvvetleri, $k$ takım ve tutucu ikilisinin eşdeğer rijitliğidir. Kontur operasyonlarında, $\delta_{x}$ ilerleme yönüdür bu yüzden işleme hatalarının üzerine etkisi göz ardı edilmektedir [6]. Bundan dolayı kontur kesme tarzı için $\delta_{y}$ 'nin sebebiyet verdiği $e_{c}$ işleme hataları dikkate alınmıştır.

$e_{c}=e^{(y)}=\delta_{y} \cos \theta$

Burada $e_{c}$ işleme hatası, $e^{(y)} y$ yönündeki takım sehiminin sebebiyet verdiği işleme hatasıdır.

Tırmanma operasyonlarında, $x$ yönündeki takım sehimi $e^{(x)}$ işleme hataları için önemli bir etkiye sahiptir [6].

$e^{(x)}=r_{b} \cos \alpha-\sqrt{r_{b}^{2}-\left(\delta_{x}+r_{b} \sin \alpha\right)^{2}}$

Burada $r_{b}$ takım yarıçapıdır. $\delta_{x}$ ve $\delta_{y}{ }^{\prime}$ den kaynaklanan işleme hatası $e_{r}$,

$e_{r}=\delta_{y} \cos \theta+r_{b} \cos \alpha-\sqrt{r_{b}^{2}-\left(\delta_{x}+r_{b} \sin \alpha\right)^{2}}$

Deneyler sonrası $x$ ve $y$ eksenlerinde elde edilen kesme kuvvetleri ve sehim değerleri Tablo 2'de verilmiştir. Tablo 2'de verilen dişbükey ve içbükey yüzey formları için kesme kuvveti ve sehim değerleri incelendiğinde kuvvet değerinin artması ile buna bağlı takım sehim değerini artırdığı gözlemlenmiştir. Dışbükey ve içbükey yüzey formu için Deney No 1'de en küçük kesme hızı, ilerleme ve yanal adım değerinde en küçük kesme kuvveti ve takım sehimi değerleri oluşmuştur. Dişbükey yüzey formunda Deney No 7 ve içbükey yüzey formunda ise Deney No 4 için en büyük kesme kuvveti ve takım sehimi meydana gelmiştir. 
Tablo 2. Deneyler sonrası dışbükey ve içbükey yüzey formu için kesme kuvveti ve sehim değerleri (Cutting force and deflection values for convex and concave surfaces of the end of experiments)

\begin{tabular}{|c|c|c|c|c|c|c|c|c|}
\hline \multirow{3}{*}{$\begin{array}{l}\text { Deney } \\
\text { No }\end{array}$} & \multicolumn{4}{|c|}{ Kontrol Parametreleri } & \multicolumn{4}{|c|}{ Ölçüm Sonuçları } \\
\hline & \multirow{2}{*}{$\begin{array}{l}\text { Kesme } \\
\text { H1z1 } V_{c} \\
(\mathrm{~m} / \mathrm{min})\end{array}$} & \multirow{2}{*}{$\begin{array}{l}\text { İlerleme } V f \\
(\mathrm{~mm} / \mathrm{min})\end{array}$} & \multirow{2}{*}{$\begin{array}{c}\text { Yanal } \\
\text { Adim } f p \\
(\mathrm{~mm})\end{array}$} & \multirow{2}{*}{$\begin{array}{c}\text { İşleme } \\
\text { Tarzı }\end{array}$} & \multicolumn{2}{|c|}{ Dışbükey Yüzey Formu } & \multicolumn{2}{|c|}{ İçbükey Yüzey Formu } \\
\hline & & & & & $\begin{array}{l}\text { Kuvvet } \\
\text { (N) }\end{array}$ & $\begin{array}{c}\text { Takım Sehimi } \delta \\
(\mathrm{mm})\end{array}$ & Kuvvet $(\mathrm{N})$ & $\begin{array}{c}\text { Takım Sehimi } \delta \\
(\mathrm{mm})\end{array}$ \\
\hline 1 & 110 & 350 & 0,8 & AYT & 268,724 & 0,08140 & 368,116 & $\mathbf{0 , 2 3 1 3 5}$ \\
\hline 2 & 110 & 382 & 1 & AYK & 378,541 & 0,30010 & 385,254 & 0,40046 \\
\hline 3 & 110 & 414 & 1,5 & TYT & 400,648 & 0,35350 & 430,664 & 0,49021 \\
\hline 4 & 110 & 445 & 2,0 & TYK & 450,675 & 0,45010 & 461,160 & $\mathbf{0 , 5 7 7 5 2}$ \\
\hline 5 & 120 & 350 & 1 & TYT & 371,000 & 0,18600 & 386,416 & 0,42215 \\
\hline 6 & 120 & 382 & 0,8 & TYK & 375,022 & 0,21010 & 372,865 & 0,29366 \\
\hline 7 & 120 & 414 & 2,0 & AYT & 480,010 & 0,47030 & 452,637 & 0,48521 \\
\hline 8 & 120 & 445 & 1,5 & AYK & 410,963 & 0,31420 & 434,205 & 0,50412 \\
\hline 9 & 130 & 350 & 1,5 & TYK & 370,006 & 0,10020 & 374,076 & 0,39512 \\
\hline 10 & 130 & 382 & 2,0 & TYT & 408,496 & 0,32140 & 454,289 & 0,49642 \\
\hline 11 & 130 & 414 & 0,8 & AYK & 371,143 & 0,25330 & 386,752 & 0,39419 \\
\hline 12 & 130 & 445 & 1 & AYT & 436,328 & 0,35210 & 377,141 & 0,29075 \\
\hline 13 & 140 & 350 & 2,0 & AYK & 394,205 & 0,29120 & 393,080 & 0,45130 \\
\hline 14 & 140 & 382 & 1,5 & AYT & 400,283 & 0,31060 & 380,539 & 0,30789 \\
\hline 15 & 140 & 414 & 1 & TYK & 378,229 & 0,19234 & 375,455 & 0,29561 \\
\hline 16 & 140 & 445 & 0,8 & TYT & 370,719 & 0,18343 & 374,351 & 0,28341 \\
\hline
\end{tabular}

Parametreler açısından değerlendirildiğinde ise yanal adım ve ilerleme parametreleri takım sehimini etkileyen en önemli faktörler olmuşlardır.

Dışbükey yüzey formu için aynı ve zıt yönlü frezeleme tekniğinde takım sehimi ve buna bağlı form hata değerleri çok yakın çıkmıştır. Dışbükey yüzey formunun işlenmesinde aynı yönlü frezeleme tekniğinde kesici takıma ait kesme kenarlarının iş parçasına üst üste bindirme yapmaktadır. Buna bağlı $x$ yönündeki kuvvetler zit yönlü frezeleme tekniğinde küçülmektedir [23]. İçbükey yüzey formunda ise aynı yönlü frezeleme tekniği için takım sehimi ve form hata değerleri küçük çıkmıştır. Kesme tarzı olarak kontur operasyonları takım sehimi ve buna bağlı form hata değerleri küçük çıkmıştır. Bunun nedeni kontur operasyonları parça eksenine paralel ve kısa süreli işlemeyi içermesidir.

\section{1 Üç Boyutlu Optik Tarama Sonuçları (Results of Three Dimensional Optical Scanning)}

Optik taramadan elde edilen model ile BDT modeli karşılaştırılmış ve parça üzerindeki takım sehiminden kaynaklanan form hataları sayısal olarak ölçülerek işaretlenmiştir. Parça üzerinde meydana gelen negatif veya pozitif form hataları ve oluştuğu bölgeler üç boyutlu optik tarama çıktıları ile gösterilmiştir. Parça üzerinde form hata değerleri renklendirmeler yardımı ile belirginleştirilmiştir. Dışbükey yüzey formu için gerçekleştirilen 16 adet tarama ve her tarama için ilgili üç boyutlu form hataları tespit edilmiştir.

Yapılan deneylerde meydana gelen en büyük ve en küçük form hata değerleri Tablo 3 'de verilmiştir. Tablo 3'de görüldüğü gibi dişbükey yüzey formu için en büyük form hatası $0,48859 \mathrm{~mm}$ ile Deney 7'de oluşmuştur. Deneysel ölçümlerden elde edilen en büyük sehim değeri (Tablo 2) yine Deney 7'de $(0,47030 \mathrm{~mm})$ aynı bölgede oluşmuştur. En küçük form hatası Tablo 3'de görüldüğü gibi $(0,04599 \mathrm{~mm})$ ile Deney 1'de oluşmuştur. Deneysel ölçümlerde (Tablo 2) ise $0,03140 \mathrm{~mm}$ ile yine benzer bölge ile Deney l'de oluşmuştur.

Tablo 3. Deneyler sonrası dışbükey ve içbükey yüzey formu için form hata değerleri (The values of form defects for convex and concave surfaces of the end of experiments)

\begin{tabular}{|c|c|c|c|c|}
\cline { 2 - 5 } \multicolumn{1}{c|}{} & \multicolumn{4}{c|}{ Form Hata Değerleri (mm) } \\
\cline { 2 - 5 } \multicolumn{1}{c|}{} & Dişbükey Yüzey Formu & \multicolumn{2}{c|}{ İçbükey Yüzey Formu } \\
\cline { 2 - 5 } \multicolumn{1}{c|}{} & $\begin{array}{c}\text { En Büyük } \\
\text { Form Hata } \\
\text { Değeri }\end{array}$ & $\begin{array}{c}\text { En Küçük } \\
\text { Form Hata } \\
\text { Değeri }\end{array}$ & $\begin{array}{c}\text { En Büyük } \\
\text { Form Hata } \\
\text { Değeri }\end{array}$ & $\begin{array}{c}\text { En Küçük } \\
\text { Form Hata } \\
\text { Değeri }\end{array}$ \\
\hline 1 & 0,09530 & $\mathbf{0 , 0 4 5 9 9}$ & 0,23856 & $\mathbf{0 , 2 0 1 8 1}$ \\
\hline 2 & 0,30904 & 0,23217 & 0,40599 & 0,33995 \\
\hline 3 & 0,34019 & 0,22840 & 0,59545 & 0,45252 \\
\hline 4 & 0,46781 & 0,39374 & $\mathbf{0 , 6 0 9 0 6}$ & 0,47788 \\
\hline 5 & 0,24358 & 0,17521 & 0,43079 & 0,39242 \\
\hline 6 & 0,27223 & 0,19020 & 0,30384 & 0,25501 \\
\hline 7 & $\mathbf{0 , 4 8 8 5 9}$ & 0,42350 & 0,49345 & 0,43119 \\
\hline 8 & 0,28417 & 0,26329 & 0,54496 & 0,49853 \\
\hline 9 & 0,11618 & 0,04602 & 0,41238 & 0,38058 \\
\hline 10 & 0,31280 & 0,24748 & 0,51448 & 0,46384 \\
\hline 11 & 0,29839 & 0,25143 & 0,43251 & 0,32940 \\
\hline 12 & 0,34366 & 0,22688 & 0,29084 & 0,20899 \\
\hline 13 & 0,30982 & 0,23750 & 0,46853 & 0,37500 \\
\hline 14 & 0,31531 & 0,34535 & 0,33268 & 0,26927 \\
\hline 15 & 0,18708 & 0,14385 & 0,30640 & 0,27814 \\
\hline 16 & 0,17932 & 0,14968 & 0,29202 & 0,25755 \\
\hline
\end{tabular}

Üç boyutlu optik tarama ve deneysel ölçüm sonuçları arasında ortaya çıkan küçük farklar deneysel ölçümlerdeki çevresel faktörlere ve ölçüm yapılan cihazların kalibrasyonlarına bağlanmıştır. Deney 7 ve Deney 1'e ait optik tarama grafik sonuçları sırasıyla 
Şekil 4(a) ve 4(b)'de verilmiştir. Dışbükey yüzey formu için üç boyutlu optik taramalardan elde edilen en büyük form hata çıktıları frezeleme pozisyon açısına göre kesme kuvvetlerinin değişimi ile Şekil 5'de verilmiştir. En küçük form hata çıtılarının meydan geldiği ilgili deney için frezeleme pozisyon açısına göre kesme kuvvetlerinin değişimi ile Şekil 6'da verilmiştir. Şekil 5 ve 6'dan görüldüğü gibi dışbükey numunenin simetrik yarısı için frezeleme pozisyon açısının $45^{\circ}-60^{\circ}$ aralığında en büyük kesme kuvvetleri ve form hata değerleri oluşmuştur. Kesici efektif çapının sıfıra yaklaştığı bölgelerde kesme kuvvetleri ve form hata değerleri azalmıştır.

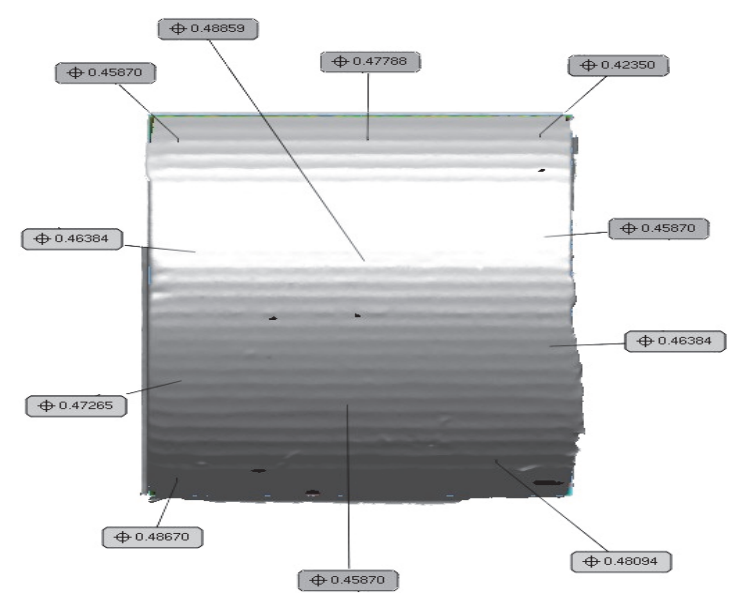

İçbükey yüzey formu içinde 16 adet gözlem gerçekleştirilmiş ve her gözlem için üç boyutlu optik tarama yapılarak form hataları tespit edilmiştir. İçbükey yüzey formu için yapılan deneylerde meydana gelen en büyük ve en küçük form hata değerleri yukarıda Tablo 3 'de verilmiştir. Deney 4 ve Deney 1'e ait optik tarama grafik sonuçları sırasıyla Şekil 7(a) ve 7(b)'de verilmiştir. Tablo 2'de görüldüğü gibi en büyük form hatası 0,60906 mm ile Deney 4'de oluşmuştur. Deneysel ölçümlerden elde edilen en büyük sehim değeri (Tablo 2) yine Deney 4'e form hatası ile aynı bölgede $0,57752 \mathrm{~mm}$ oluşmuştur.

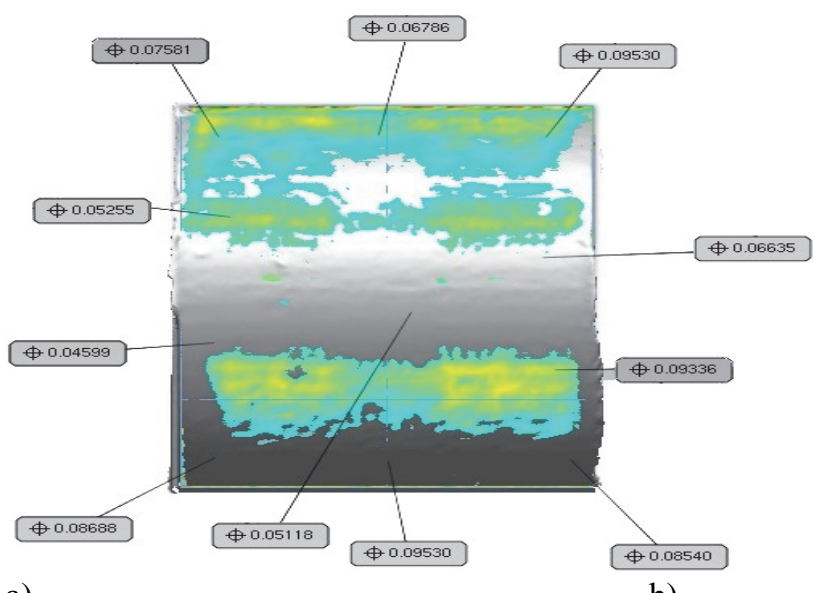

a)

b)

Şekil 4. Dışbükey yüzey form hataları: a) en büyük form hatası (Deney 4), b) en küçük form hatası (Deney 1) (The form defects for convex surface the largest form defect (Experiment 7) a), the smallest form defect (Experiment 1) b))
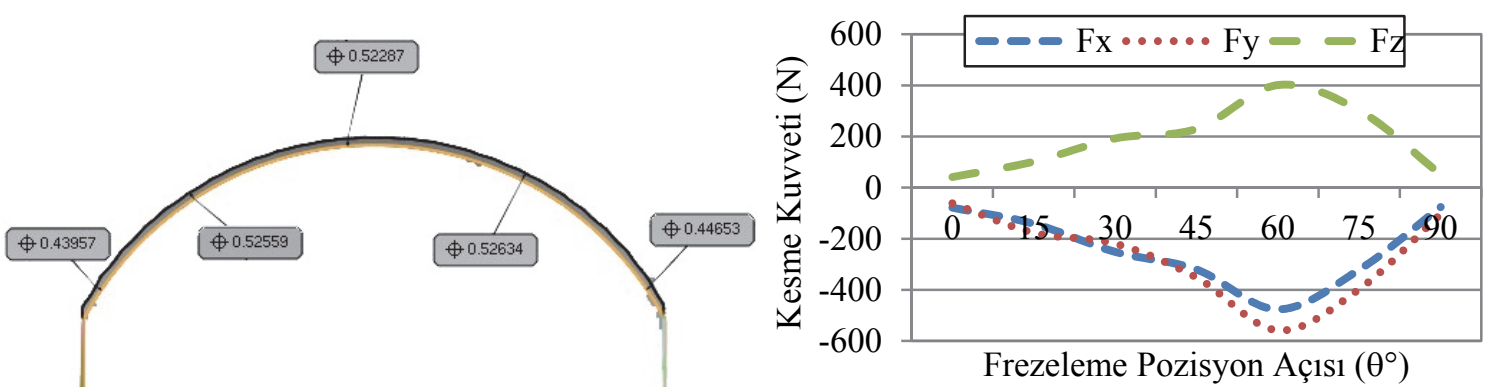

Şekil 5. Dışbükey yüzey formunun en büyük form hatası için frezeleme pozisyon açısına göre kesme kuvvetlerinin değişimi (Variation of cutting forces according to milling position angle for the largest form defect of convex surface type)
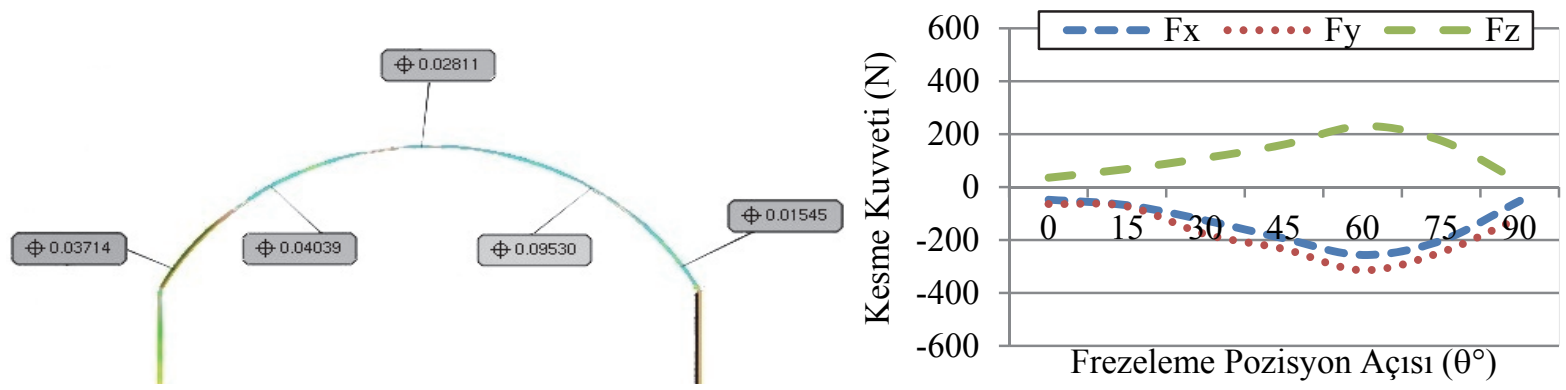

Şekil 6. Dışbükey yüzey formunun en küçük form hatası için frezeleme pozisyon açısına göre kesme kuvvetlerinin değişimi (Variation of cutting forces according to milling position angle for the smallest form defect of convex surface type) 
En küçük form hatası Tablo 3'de görüldüğü gibi 0,20181 mm ile Deney 1'de oluşmuştur. Deneysel ölçümlerde (Tablo 2) ise 0,23135 mm ile yine Deney 1 'de oluşmuştur. Üç boyutlu optik tarama ve deneysel ölçüm sonuçları arasındaki ortaya çıkan küçük farklar deneysel ölçümlerdeki çevresel faktörlere ve ölçüm yapılan cihazların kalibrasyonlarına bağlanmıştır. İçbükey yüzey formu için üç boyutlu optik taramalardan elde edilen en büyük form hata çıtıları frezeleme pozisyon açısına göre kesme kuvvetlerinin değişimi ile Şekil 8'de verilmiştir. İçbükey yüzey formunda en küçük form hata çıktılarının meydan geldiği ilgili deney için frezeleme pozisyon açısına göre kesme kuvvetlerinin değişimi ile Şekil 9'de verilmiştir. Şekil 8 ve 9'dan görüldüğü gibi içbükey numunenin simetrik yarısı için frezeleme pozisyon açısının $45^{\circ}-60^{\circ}$ aralığında en büyük kesme kuvvetleri ve form hata değerleri oluşmuştur. Kesici efektif çapın sıfira yaklaştığı bölgelerde kesme kuvvetleri ve form hata değerleri azalmıştır. Takım temas uzunluğu efektif çapın büyüdüğü pozisyon açılarında büyümüş, bu durum kesme kuvvetlerini ve buna bağlı form hatalarını artırmıştır.
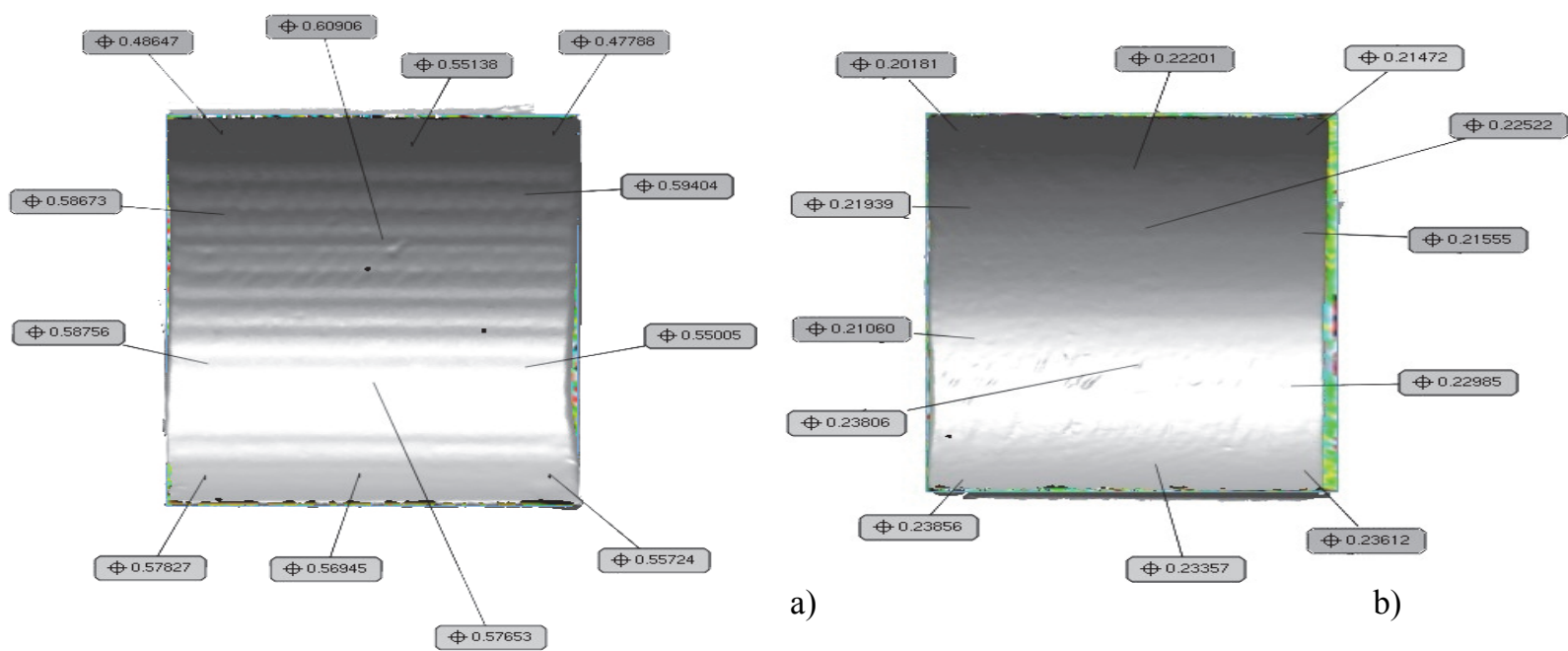

Şekil 7. İçbükey yüzey form hataları: a) en büyük form hatası (Deney 4), b) en küçük form hatası (Deney 1) (The form defects for concave surface: the largest form defect (Experiment 4) a), the smallest form defect (Experiment 1) b))
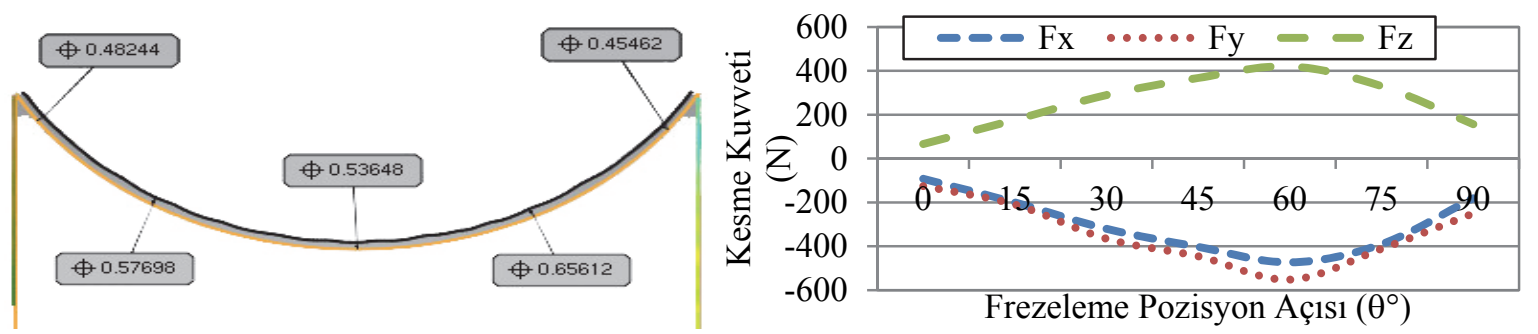

Şekil 8. İçbükey yüzey formunun en büyük form hatası için frezeleme pozisyon açısına göre kesme kuvvetlerinin değişisimi (Variation of cutting forces according to milling position angle for the largest form defect of concave surface type)
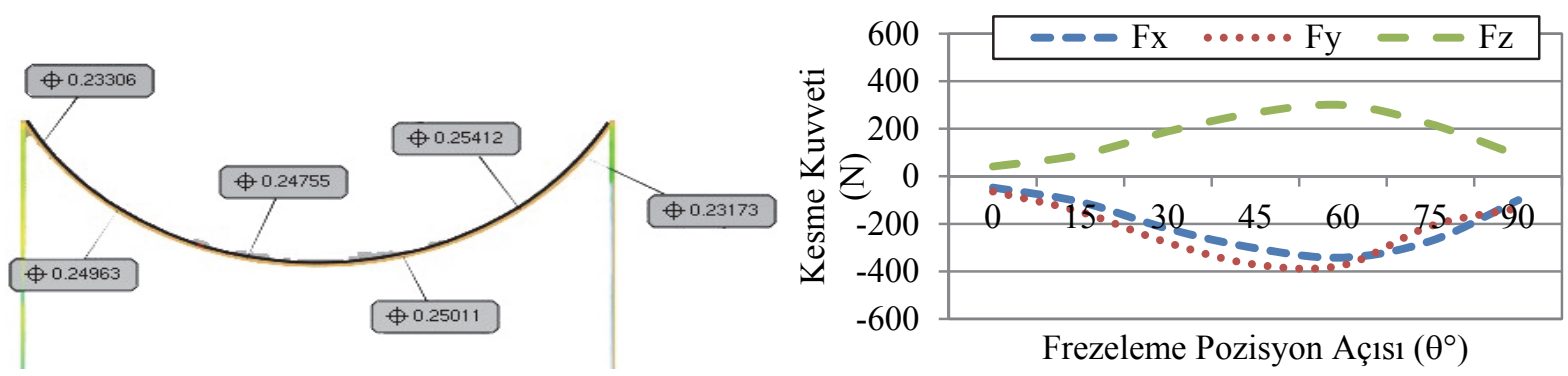

Şekil 9. Dışbükey yüzey formunun en küçük form hatası için frezeleme pozisyon açısına göre kesme kuvvetlerinin değişimi (Variation of cutting forces according to milling position angle for the smallest form defect of concave surface type) 

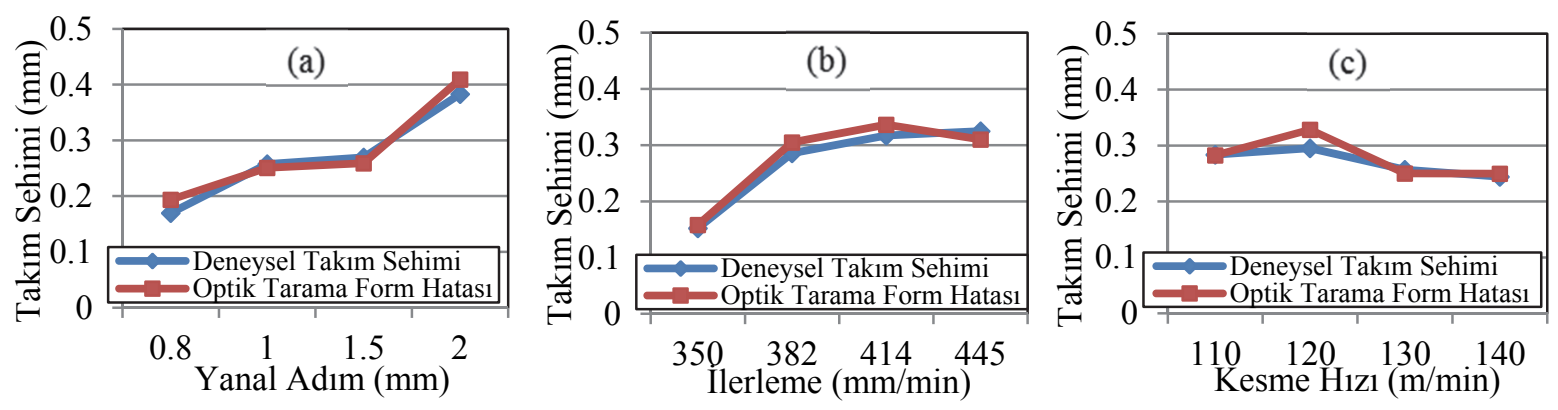

Şekil 10. Deneysel takım sehimi ve form hatalarının karşılaştırılması: a) yanal adım, b) İlerleme, c) kesme hızı (Comparison of experimental tool deflection and form defects: step over a), feedrate b), cutting velocity c))
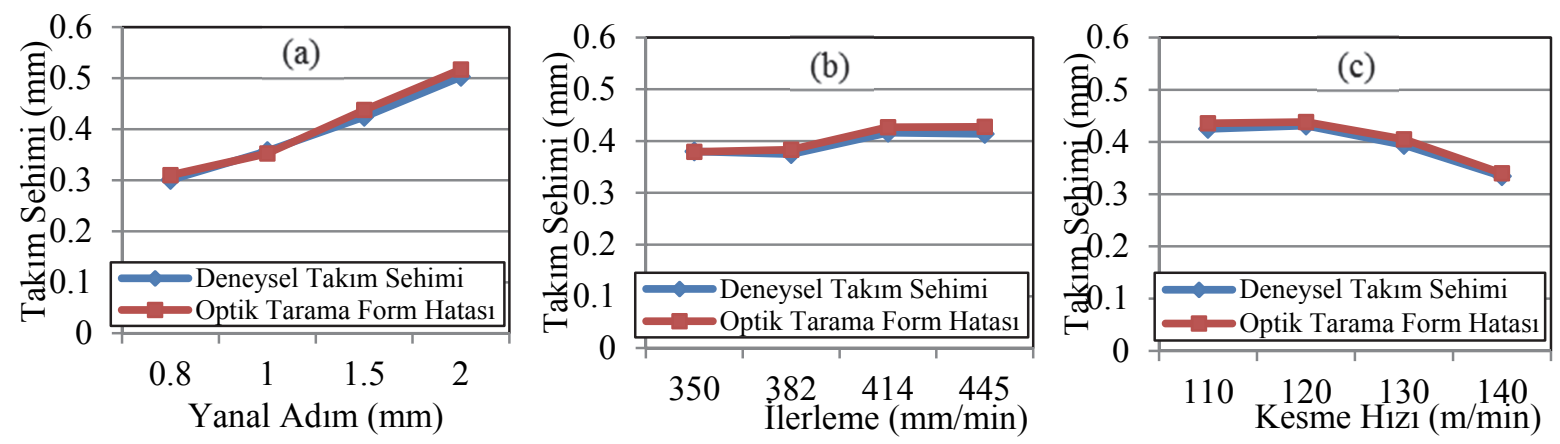

Şekil 11. Deneysel takım sehimi ve form hatalarının karşılaştırılması: a) yanal adım, b) İlerleme, c) kesme hızı (Comparison of experimental tool deflection and form defects: step over a), feedrate b), cutting velocity c))

Dişbükey ve içbükey yüzeyler için meydana gelen takım sehimi ve buna bağlı form hata değerlerinin işleme yüzeyinde oluşum yerleri incelendiğinde, genel olarak takımın tırmanma ve inme yaptığ bölgelerde maksimum takım sehim değerlerinin oluştuğu göze çarpmaktadır (Şekil 5, 6, 8, 9). Takım efektif çapının azaldığı bölgelerde ise sehim ve form hata değerlerinin azaldığ görülmektedir.

\section{DEĞERLENDİRME (EVALUATION)}

Her iki yüzey formu için ölçülen sehim değerlerinin, taramalar sonucunda elde edilen form hata değerleri ve bölgeleri ile yakinen örtüştüğü Şekil 7 ve 10'da görülmektedir. Taramalar dikkatli incelendiğinde parçaların en üst bölgesinde kesicinin efektif çap değeri sıfıra yaklaştığ 1 için kuvvet değerlerine bağlı takım sehimi azalmış ve buna bağlı form hataları da azalma göstermiştir. Dışbükey ve içbükey yüzeyler için parametreler açısından meydana gelen en büyük form hata bölgeleri ve deneysel takım sehim değerleri karşılaştırıldığında ise Şekil 10-11(a) ve(b) incelendiğinde yanal adım ve ilerleme değeri artıkça takım sehimi artmış ve buna bağlı form hatası da artış göstermiştir. Hemen hemen deneysel takım sehimi kadar, parça üzerinde form hatası oluşmuştur. Şekil 10-11(c) incelendiğinde ise kesme hızının artması ile deneysel takım sehim değeri azalmış ve buna bağlı form hataları da azalmıştır.

\section{SONUÇLAR (RESULTS)}

Deneysel çalışmalar neticesinde yanal ilerleme ve ilerleme değerlerinin artması ile takım sehimi ve buna bağlı form hataları artış göstermiştir. Elde edilen bulgular literatür [24] sonuçları ile yakinen örtüşmüştür. Literatürde [24], ilerleme hızının artması ile takım sehiminin arttığına ulaşılmış ve yapılan çalışma paralel sonuçlar vermiştir. Ikua vd. [6] benzer sonuçlarla desteklemişlerdir. Ek olarak parça eksenine paralel takım yolu hareketlerinin, talaşın kesme bölgesinden kolay atılmasında önemli bir etmen olduğunu vurgulamışlar bu sonuç elde edilen veriler ile yakinen örtüşmüştür. Eğimli yüzey üzerinde takım frezeleme pozisyonu arttıkça takım sehimi ve buna bağlı form hatasının arttığ1 görülmüştür. $45^{\circ}-60^{\circ}$ frezeleme pozisyon açısı aralığında en büyük form hataları oluşmuş, takım efektif çapının sıfır olduğu noktalara doğru azalmıştır. Efektif çapın sıfır olduğu noktalarda kesici takım temas uzunluğu azalmış ve kesme kuvvetlerini azaltmıştır. Fakat kesme kuvvetleri ve buna bağlı takım sehiminin büyüdüğü noktalarda $\left(45^{\circ}-60^{\circ}\right)$ efektif çapın büyüdüğü, dolayısı ile temas uzunluğunun büyüdüğü ortaya çıkmıştır. Kim vd. [7], çalışmalarında, frezeleme pozisyon açısı 
artıkça takım sehimi ve buna form hataları arttığını ortaya koymuş, çalışmada paralel sonuçlara ulaşılmıştır. Yine yapılan çalışmada, Toh [25], tespit ettiği kuvvetlerin takımın eğim açısının büyümesi ile arttığını desteklemiş ve çalışmamız ile paralellik göstermiştir.

Sonuç olarak;

- Deneysel çalışmada, endüktif sensörler yardımı ile işleme esnasındaki dinamik takım sehiminin tespit edilebileceği ve form hatlarının tespitinde üç boyutlu optik tarama sistemlerinin kullanabilirliği ortaya koyulmuştur.

- Yanal adim ve ilerleme parametreleri kesme kuvvetleri ve buna bağlı takım sehimi üzerine en etkili parametreler olarak bulunmuştur. Dişbükey yüzey formlarının işlenmesi takım sehimi ve form hataları açısından yüksek doğruluğa sahip çıkmıştır.

- Dişbükey ve içbükey yüzey formu için zit yönlü frezeleme tekniğinde takım sehimi ve buna bağlı form hata değerleri aynı yönlü frezelemeye göre yüksek çıkmıştır. Nedeni ise hem yüzeyin formu hem de takımın az talaştan çok talaşa doğru girmesi kesme kuvvetlerini artırmış ve takım boyunun uzun olmasından dolayı tırlama titreşimi oluşturmuştur. Aynı zamanda yapılan çalıșmalarda, aynı yönlü frezeleme tekniğinde daha az kesme kuvveti oluştuğu vurgulanmıştır. Kesme kuvvetlerinin düşük olması takım sehiminin azalmasını sağlamıştır.

- Kesme tarzı olarak kontur operasyonları takım sehimi ve buna bağlı form hataları açısından küçük çıkmıştır. Çünkü kontur operasyonları kavis eksenine paralel ve kısa süreli işlemeyi içermektedir. Yapılan çalışmalarda, kavis eksenine paralel çalışmaların talaşın kesme bölgesinden kolay uzaklaştırılmasını sağladığ vurgulanmıştır.

- Eğimli yüzey üzerinde takım frezeleme pozisyonu arttıkça takım sehimi ve buna bağlı form hatasının arttığ 1 görülmüştür. $45^{\circ}-60^{\circ}$ frezeleme pozisyon açısı aralığında en büyük form hataları oluşmuş, takım efektif çapının sıfır olduğu noktalara doğru azalmıştır. Efektif çapın sıfır olduğu noktalarda kesici takım temas uzunluğu azalmış ve kesme kuvvetlerini azaltmıştır.

\section{TEŞEKKÜR (ACKNOWLEDGMENT)}

$\mathrm{Bu}$ çalışmaya, maddi destek sağlayan Defne Mühendislik Şirketine, Karabük Üniversitesi Bilimsel Araştırma Proje Birimine ve Teknolojik bilgi sağlayan Prof. Dr. Mustafa KURT’a teşekkür ederiz.

\section{KAYNAKLAR (REFERENCES)}

1. Trent, E.M., Wright, P., "Metal cutting", Butterworths Press, $4^{\text {th }}$ Edition, London, 2000.
2. Zhou, J.M., Andersson, M., Ståhl, J.E., "Identification of cutting errors in precision hard turning process", Journal of Materials Processing Technology, 153-154, 746-750, 2004.

3. Shaw, M.C., "Metal cutting principles", Oxford University Press, $2^{\text {nd }}$ Edition, Oxford, 2005.

4. Kim, S.W., Choi, Y.B., Oh, J.T., "Reverse engineering: high speed digitization of free-form surfaces by phase-shifting grating projection moiré topography", International Journal of Machine Tools and Manufacture, Volume 39, Issue 3, pp. 389-401, 1999.

5. Broggiato, G.B., Campana, F., Gerbino, S., "Shape deviation analysis on sheet-metal parts through reverse engineering techniques", XII ADM International Conference-Italy-Sept, 5th-7th, 2001.

6. Ikua, B.W., Tanaka, H., Obata, F., Sakamoto, S., "Prediction of cutting forces and machining error in ball end milling of curved surfaces -I theoretical analysis", Precision Engineering, 25: 266-273, 2001.

7. Kim, G.M., Kim, B.H., Chu, C.N., "Estimation of cutter deflection and form error in ball end milling processes", Machine Tools \& Manufacture, 43:917-924, 2003.

8. Lacalle, L.N.L., Lamikiz, A., Sanchez, J.A., Salgado, M.A., "Effects of tool deflection in the high-speed milling of inclined surfaces", The International Journal of Advanced Manufacturing Technology, 24:621-631, 2004.

9. Zhang, X.F., Xie, J., Xie, H.F., Li, L.H., "Experimental investigation on various tool path strategies influencing surface quality and form accuracy of CNC milled complex freeform surface", The International Journal of Advanced Manufacturing Technology, 58, 5-8, 647-654, 2012.

10. Elmas, S., Islam, N., Jackson, M.R., Parkin, R.M., "Analysis of profile measurement techniques employed to surfaces planed by an active machining system", Measurement, 44, 365-377, 2011.

11. Vorburger, T.V., Rhee, H.G., Renegar, T.B., Song, J.F., Zheng, A., "Comparison of optical and stylus methods for measurement of surface texture", The International Journal of Advanced Manufacturing Technology, 33, 1-2, 110-118, 2007.

12. Lin, A.C., Chin, C.H., "Automatic $3 \mathrm{D}$ measuring system for optical scanning of axial fan blades", The International Journal of Advanced Manufacturing Technology, 57, 5-8, 701-717, 2011.

13. Huang, P.S., Zhang, C., Chiang, F.P., "Highspeed 3-D shape measurement based on digital fringe projection". Optical Engineering, 42, 163, 2003. 
14. Quan, C., He, X.Y., Wang, C.F., Tay, C.J., Shang, H.M., "Shape measurement of small objects using LCD fringe projection with phase shifting", Optics Communications, 189, 21-29, 2001.

15. Chen, L.C., Huang, C.C., "Miniaturized 3D surface profilometer using digital fringe projection", Measurement Science and Technology, 16, 1061-1068, 2005.

16. Kurt, M., Hortomacioğlu, S., Mutlu, B., Köklü, U., "Minimization of the surface roughness and form error on the milling of free-form surfaces using a grey relational analysis" Materiali in Tehnologije/Materials and Technology, 46:3, 205-213, 2012.

17. Gologlu, C., Mizrak, C., "Bulanık mantık ve taguchi yaklaşımlı müşteri istemli ürün belirleme", Journal of The Faculty of Engineering and Architecture of Gazi University, 25(1), 9-19, 2010.

18. Motorcu, A.R., "Ç1050 ve Ç4140 çeliklerinin seramik takımlarla işlenmesinde optimum takım ömrünü sağlayan parametrelerin Taguchi yöntemiyle belirlenmesi ve takım aşınmalarının incelenmesi", Journal of The Faculty of
Engineering and Architecture of Gazi University, 24(4), 699-708, 2009.

19. Breuckmann precision in 3D, Products, 2012. (Erişim;http://www.breuckmann.com/en/industryechnology/products/optotop-he.html)

20. Defne Mühendislik, Tasarım, Ürün Geliştirme ve İmalat ve Sanayi LTD. ŞTİ., 2012.

21. The Basics Of Photo Grammetry, Geodetic Services, Inc, 2012. (www.geodetic.com)

22. CATIA V5R17, Dassault Systemes, 2012.

23. Uçar, M., Ay, M., "Parmak Freze İle Kanal Ve Alın Yüzey İşlemede Takım Ekseni İle İşlenen Yüzey Arasındaki Paralelliğin Bozulmasına Etki Eden Kesme Parametrelerinin İncelenmesi", Makina-İmalat Teknolojileri Sempozyumu, 14-15 Ekim, Konya, Türkiye, pp. 10-16, 1999.

24. Bagc1, E., "Monitoring and analysis of MRRbased feedrate optimization approach and effects of cutting conditions using acoustic sound pressure level in free-form surface milling", Scientific Research and Essays, Vol., 6(2), pp. 256-277, 18 January, 2011.

25. Toh, C.K., "A Study of the Effects of Cutter Path Strategies and Orientations in Milling", Journal Of Materials Processing Technology, 152:346356, 2004. 